\title{
USING METAPHOR TO EXPLORE THE ORGANIZATIONAL PATTERNS OF EXPOSITORY WRITING ${ }^{1}$
}

\author{
Emilia Castaño \\ Universidad de Barcelona \\ e.castano@ub.edu \\ Isabel Verdaguer \\ Universidad de Barcelona \\ i.verdaguer@ub.edu \\ Joseph Hilferty \\ Universidad de Barcelona \\ hilferty@ub.edu
}

\begin{abstract}
Writing is a complex and multifaceted task that presents many challenges, especially when writing in a foreign language. Recent studies have shown that writers and readers benefit from explicit knowledge of text genres and their organization, since the sense of unity that is sought in a text is largely connected to its overall structure. Awareness of text structure informs about conventions of structure that control the flow of information and determine the kinds of cues available to readers. In the present article, we use conceptual metaphor theory to provide a new way of exploring the activity of writing in the academic context and tap into the conceptual frame that writers and readers of expository texts may employ to organize information. In this sense, we illustrate how the TEXTS ARE JOURNEYS metaphor can be used to elucidate the rationale behind the macrostructural organization of expository texts written by non-expert EFL writers.
\end{abstract}

KEYWORDS: text structure, conceptual metaphor, academic writing, academic reading, expository texts, EFL.

1. We acknowledge the support of the Agència de Gestió d'Ajuts Universitaris i de Recerca (2014 SGR 1374) and the Fundación Obra Social la Caixa and Universitat de Barcelona (LCF/PR/ PR06/11010001, grant held by Emilia Castaño). 


\section{EL USO DE LA METÁFORA PARA EXPLORAR LOS PATRONES ORGANIZATIVOS DE LA ESCRITURA EXPOSITIVA}

RESUMEN: La escritura es una tarea compleja y multifacética que presenta muchos desafios, especialmente cuando se escribe en un idioma extranjero. Estudios recientes han demostrado que tanto escritores como lectores se benefician del conocimiento explícito de los géneros textuales y de su organización, ya que el sentido de unidad de un texto está en gran parte relacionado con su estructura general. El conocimiento de la estructura del texto revela las convenciones que controlan el flujo de información y determinan los tipos de señales disponibles para los lectores. En este artículo usamos la teoría de la metáfora conceptual para proporcionar una nueva forma de explorar la escritura en el contexto académico $y$ analizar el marco conceptual que escritores y lectores emplean para organizar la información. En este sentido, ilustramos cómo la metáfora los TEXTOS SON VIAJES puede usarse para dilucidar la organización macroestructural subyacente en textos expositivos escritos por aprendices de inglés.

PALABRAS CLAVE: estructura textual, metáfora conceptual, escritura académica, textos argumentativos, EFL.

\section{L'USAGE DE LA MÉTAPHORE POUR EXPLORER LES MODÈLES D'ORGANISATION DES TEXTES EXPOSITIFS}

RÉSUMÉ : L'écriture est une tâche complexe et multiforme qui présente de nombreux défis, en particulier lorsque vous écrivez dans une langue étrangère. Des études récentes ont montré que les auteurs et les lecteurs tirent un grand profit de la connaissance explicite des genres textuels et de leur organisation, le sens de l'unité d'un texte étant largement lié à sa structure générale. La connaissance de la structure du texte révèle les conventions qui contrôlent le flux d'information et déterminent les types de signaux disponibles pour les lecteurs. Dans cet article, nous utilisons la théorie de la métaphore conceptuelle pour proposer un nouveau moyen d'explorer l'écriture dans un contexte universitaire et exploiter le cadre conceptuel utilisé par les auteurs et les lecteurs pour organiser l'information. Dans ce sens, nous illustrons comment la métaphore les TEXTES SONT DES VOYAGES peut être utilisée pour élucider l'organisation macrostructurale sous-jacente dans des textes expositifs écrits par des apprenants de la langue anglaise.

MOTS CLÉS: structure textuelle, métaphore conceptuelle, écriture académique, textes expositifs, EFL.

Recibido: 18/06/2018. Aceptado: 10/12/2018 


\section{Introduction}

Recent years have seen a growing consensus among writing specialists that L2 learners profit greatly when they possess a clear understanding of text structure (see, e.g., Matsuda, Canagarajah, Harklau, Hyland and Warschauer 2003; Hyland 2007). Awareness of text structure informs students about the sense of unity that is sought in a text, connected not only to its local organization, but also to its overall structure. This positive impact on their written production seems to be motivated by the fact that knowledge of text structure influences learners' perception of what to do during the three main stages of writing activity: planning, translating (i.e., formulation) and reviewing (Flower and Hayes 1981). This has led many researchers to emphasize the need for ESL writers to learn how to organize English written discourse. In fact, knowledge of text structure offers two benefits. On the one hand, it has been proved that there is a causal relationship between text structure awareness and improvement in composition skills (Dickson, Simmons and Kameenui 1995; Raphael and Englert 1990; Wong 2000). On the other, explicit knowledge of text organization has been shown to have a positive effect on both young and mature readers' comprehension and recall (Meyer, Talbot, Poon and Johnson 2001; Meyer and Poon 2004; Richardson and Morgan 2003). As Pearson and Raphael (1990) point out, readers who have a clear understanding of the various types of text structure comprehend texts better (see also Ghaith and Harkouss 2003; Goldman and Rakestraw 2000; Kusiak-Pisowacka 2016; Salmani-Nodoushan 2010; Vahidi 2008). This seems logical, if we take into account that text comprehension involves the construction of a coherent cognitive representation of the text content rather than of its surface form (Murray 1997; Sanders and Noordman 2000; Van den Broek 1999; Virtue, van den Broek and Linderholm 2006; Zwaan and Singer 2003) and that text structure actively contributes to enhancing coherence (Kibble and Power 2004; Sanders and Noordman 2000). In addition, it has been shown that recognizing text organization is one of the most difficult reading skills for learners (Floris and Divina 2009).

In expository writing, extensively used in academic and professional settings, organization is particularly important, since these types of texts tend to deal with topics that are not directly related to personal experience and to the present time and place. Moreover, they can accomplish different functions depending on the writer's purpose, which leads them to adopt multiple structural patterns, such as (a) sequence, (b) description, (c) comparison-contrast, (d) cause-effect, and (e) problem-solution (Meyer 1999; Young and Hadaway 2006). That is why 
identifying the most common structural patterns that writers use to explain, describe or inform about a topic and raising awareness of them becomes crucial for the command of expository writing skills and the enhancement of reading comprehension.

Current writing methodologies do not take into account the potential impact that writers' metaphorical conceptualization of the notion of discourse may have on their expectations about how a text should be organized or the benefits that the use of metaphors to account for text structure may bring to the understanding, analysis and teaching of text structure. Given the abstract character of the composing process, metaphors can not only help to disentangle what writing means to writers, either expert or novice and how they approach the act of creating a text, but also to analyze and communicate the purposes and processes involved in text organization through more familiar experiences. Even though the use of metaphors to describe intellectual activity and composition processes has been previously analyzed (Tomlinson 2005; Eubanks 2011), to our knowledge, the ability of those metaphors to generate inferences about text organization and make discourse structure more transparent has not been explored yet. Only a couple of studies on the interface between text structure and conceptual metaphor have shown that expert writing can be metaphorically conceived as journeying and that this metaphor offers an enlightening insight into text organization (Castaño 2012; Castaño et al. 2013). In this context, the present article analyzes to what extent the metaphorical construal of composition and discourse as a journey can also serve as an analytical tool for the organizational patterns of a corpus of expository texts created by a group of novice writers and highlights its potential as a medium for teaching text structure.

In what follows an outline of the main theoretical issues that will lay the foundations of our analytical framework is offered. Special attention is paid to how conceptual metaphor can contribute to providing a satisfactory top-down analysis of the narrative flow and organizational characteristics of expository texts that rests on the interface between language, cognition and bodily experience, and to shedding light both on the process of text generation and reading comprehension.

This paper is structured in the following way: In section 2 we briefly introduce its theoretical framework, the Cognitive Theory of Metaphor. Next, we describe the methodology we have used in our research, based on corpus linguistics. Then, we present our analysis of the students' texts. In section 5 we discuss our findings, leading to our conclusions in the final section. 


\section{Theoretical framework}

From the advent of the Cognitive Theory of Metaphor (Lakoff and Johnson 1980) in the early 1980s, the locus of metaphor shifted from language to thought, giving way to a new conceptualization of metaphor that departs drastically from its classical conception as an embellishing literary trope. Unlike previous theories of metaphor, the Cognitive Theory of Metaphor emphasizes its role as a cognitive operation whereby two domains, a source domain -typically a concrete conceptand a target domain -often an abstract or less organized concept- are mapped in such a way that we can understand, reason and speak about the target domain in terms of the source domain (Lakoff 1993; Lakoff 2014; Semino 2008; Hampe 2017). This grants metaphor a key role in the development and understanding of abstract concepts, which depends on the metaphorical expansion of concepts whose roots rest on our embodied experience (i.e. on the particular characteristics of our bodies and how they shape the way we interact with the environment). Under this premise, metaphor is claimed to determine, at least partially, the meaning of abstract concepts and structure how we think about them, to the extent that metaphors often impose organization on many domains of our everyday life (Lakoff 1987; Lakoff and Johnson 1980; inter alia). Consider the simple case of a traditional house thermometer. Typically, such thermometers are placed vertically so that ambient temperature is reflected by the level of liquid in the glass tube. Of course, thermometers do not need to be positioned vertically in order to work, as traditional medical thermometers readily show. It merely seems natural for house thermometers to be placed vertically. The reason is nothing other than the metaphor MORE IS UP/LESS IS DOWN is thoroughly entrenched in our conceptual system and imposes structure on the world around us. Hence, we argue that just as the conceptual metaphor MORE IS UP/LESS IS DOWN makes it natural for us to place a thermometer vertically on a wall and inspires more satisfactory interface designs (Hurtienne and Blessing 2007), our metaphorical conceptualization of the process of composing and discourse can also guide the way we structure texts.

Conceptual metaphor theory has been applied to discourse studies to assess its cognitive effects on text comprehension, on the one hand, and on content depiction modeling, on the other. As regards the influence of metaphor on information processing and text representation, evidence suggests that texts written around a main conceptual metaphor provide a schema-like structure that helps readers in a decisive manner to filter and organize incoming information as well as to link pieces of information in memory (Allbritton 1995; Allbritton, McKoon and Gerrig 1995; Lau and Schlesinger 2005; Robins and Mayer 2000). Evidence not 
only grants metaphor a prominent role in the way information is managed and integrated by the listener/reader but also in the way it is presented by the speaker/ writer. At the content level, Ponterotto (2003), for example, has shown that the description of a topic is quite often organized around a network of thematically related metaphors whose function is to support a superordinate metaphor, which provides the "heuristic frame" (i.e., the strategy to construct arguments and make difficult notions more accessible) for the whole conversation. In the same vein, further research has also pointed out that the plot development of written texts such as magazine articles, scientific papers (Ponterotto 2007; Semino 2008) or literary works (Peña Cervel 2011) is also influenced by metaphor, which helps to frame their content in particular ways and aids semantic coherence (Goatly 1997; Ponterotto 2007; Semino 2008).

Despite the fact that the power of metaphor to determine the way people perceive, interpret and verbalize their experiences and thoughts is more and more acknowledged, little attention has been paid to the possibility that, beyond topic description, metaphor can also influence the organization and macrostructure of the text as a whole. To our knowledge, only Kimmel $(2005,2008,2013)$ has addressed how conceptual metaphor and its underlying image schemas work as narrative structuring devices used to scaffold the story macrostructure. In his analysis of Heart of Darkness, for instance, he shows how the metaphor selFTRANSFORMATION IS A JOURNEY sets the basis for the general flow contours of a novel whose overarching organization follows a journey-based structure.

All in all, these studies seem to strengthen the idea that, given the ability of metaphor to impose structure on the way we understand and think about the world around us, it not only helps writers to frame the way a topic is linguistically described but also to organize information.

Texts are the material expression of the reasoning process that the author conducted to verbalize an idea, which brings to text not only the writer's knowledge of the subject matter to be written about but also the procedure that he followed to organize his ideas. If, as stated by Johnson (1987), reasoning is a form of motion along a path where propositions are the locations which we start out from, proceed through, and wind up at, writing can be conceived as journeying. The pairing between the source domain (i.e., a journey) and the target domains (composing a discourse) is determined by the experiential correlation between the source and target domains (Lakoff 1987). The common purpose of a journey, which is to arrive at a particular place, correlates with the purpose of writing a text, which is to reach a particular conclusion. 
Thus, the conceptualization of writing as journeying results logical as well as it does that the major structural components of a text (introduction, development, and conclusion) correlate with the three major stages of a journey: source, path, and goal. This conception of text structure constitutes a sort of "journey," so to speak: it starts out from premises and moves towards conclusions by means of logical arguments. The underlying or initial premises and presuppositions represent a starting point; the arguments that we forge correspond to paths to a solution; knowledge gaps or difficulties are deemed to be obstacles to be overcome; and, finally, the persuading evidence is the force that leads to a conclusion. All this is compressed into words and conveyed through discourse. Such correspondences might indicate that metaphors for both the composing process and the reasoning that accompanies it play an important role in determining the organization and sequencing of ideas in a text, which rests prototypically on the main metaphor TEXTS ARE JOURNEYS (see table 1). In this view, metaphor would have a multilayered impact on texts: on the one hand, it would influence its content (i.e., the authors' perspective and wording) and, on the other, its structure (i.e., the content arrangement strategy).

To be sure, the SOURCE-PATH-GOAL is flexible enough to allow for other possible elaborations. Hence, it has the suitable properties to act as a macrostructural template that can be adapted in accordance with the function of the text.

\section{Table 1. Source-to-Target Domain Correspondences}

\begin{tabular}{|ll|}
\hline Source domain: & Target domain: \\
Journeys and Force dynamics & Discourse/text \\
Source/source of an effect & $>$ Previous research or premises \\
Guide & $>$ Writer \\
Locations & $>$ Ideas, arguments \\
Trajectory & $>$ Ideas, arguments set up in spatial configuration \\
Vehicle & $>$ Means and methods for achieving an explanation \\
& $>$ Or testing hypotheses \\
Obstacles/counter-forces & $>$ Dismissal of arguments and presentation of new \\
Changes in direction & ones \\
Setting an intended target & $>$ Presenting a problem and commitment to solve it \\
Forces that lead to the goal & $>$ Evidence and findings \\
Goal & $>$ Conclusions
\end{tabular}


Despite the fact that metaphor is fundamental both to our language and conceptual systems, by no means is it claimed here that our understanding of writing is exclusively metaphorical nor that the metaphor WRITING IS JOURNEYING constitutes the only way of conceptualizing the process of composing. In fact, previous research has shown that our everyday figurative language for writing also includes metaphors such as WRITING IS FINDING A VOICE, WRITING IS TO GET IDEAS ACROSS (Conduit metaphor), WRITING IS MUSIC Or WRITING IS TRANSCRIBING, to mention but a few (Elbow 2006; Eubanks 2011; Tobin 1989; Tomlinson 2005). However, when it comes to text organization, given that information sequencing correlates with time and time is metaphorically conceptualized as motion in space, the WRITING IS JOURNEYING metaphor can be particularly useful to articulate our understanding of text structure. That is why we resort to this metaphor to explore how structure is bestowed on non-expert expository writing and argue that the inferences derived from the logic of journeys can be carried over to the analysis of text structure and, hence, that conceptual metaphor theory provides a promising approach to the study of text organization.

\section{Methodology}

In what follows, we provide a detailed top-down qualitative analysis of the macrostructure of the texts included in the subcorpus of Spanish EFL learners majoring in engineering, compiled by our research group, and which is a part of the learner corpus VESPA (Varieties of English for Specific Purposes Database, https://www.uclovain.be/en-cedl-vespa.html), coordinated by the Catholic University of Louvain. The objective of the project VESPA is the compilation and analysis of a corpus of learners for specific purposes, in order to identify and analyze the difficulties of speakers of different mother tongues when writing academic texts in English. This subcorpus consists of 90 texts and approximately 650.000 tokens. The learners' level of proficiency in English is B1 according to the Common European Framework of Reference for Languages (CEFR). Thus, they were expected to be able to write straightforward connected texts on a range of familiar subjects within their field of interest.

Our analysis provides a cognitive interpretation of text structure based on the use of conceptual metaphor as an analytic tool to uncover the organizational patterns of expository texts. This approach was selected because, as argued by Sanders and Schilperoord (2006), text analysis can be effectively used to reveal the rules writers followed in composition as well as traces of their cognitive representation. To 
achieve this goal, the metaphors WRITING IS JOURNEYING and TEXTS ARE JOURNEYS are taken as a starting point. This choice is motivated by two factors, on the one hand, the fact that previous research on the metaphorical conceptualization of writing has shown that these metaphors are deeply entrenched in our conceptualization of writing (Tobin 1989; Tomlinson 2005); and, on the other, the presence in the corpus under analysis of lexical cues that elicit an interpretation of text organization connected to the metaphor WRITING IS JOURNEYING. Among those lexical cues we can find expressions that present the text as a sequence of locations and arguments/ evidence as guiding entities -"this paper can be divided into four stages that will constitute the following chapters in this work" (UBA0024-ENG-01); "Throughout the paper an analysis of ... will be developed" (UBA0062-ENG-01) "Down below there is a table where can be seen the inputs and the outputs in each equipment step by step" (UBA0085-ENG-01); "an exhaustive study of the process leads to conclude that..." (UBA0093-ENG-01). Other expressions depict discourse progress as a succession of steps or stages towards an intended goal - "the very first step towards the analysis provided below is..." (UBA0040-ENG-01); "the methodology comprises the following steps" (UBA0012-ENG-01); "the results will be exposed further on" (UBA0027-ENG-01); "the final goal of this paper will be..." (UBA0032-ENG-01).

To conduct our analysis, we proceeded as follows:

1. The overall rhetorical purpose of each text was identified by means of a close reading of the essays, which led to their classification into analytical and analytical-argumentative essays.

2. Each text was examined to identify the structure and the internal discourse segments of each text on the basis of their function. Text fragmentation was individually conducted by three experts and inter-rater reliability was checked to confirm that there was agreement on their judgments. Divergences among experts were solved by further discussion.

3. The most common organizational strategies used by writers were identified.

4. The general patterns of discourse organization across all the text in the corpus were described and accounted for from the point of view of conceptual metaphor theory.

\section{Text analysis}

Our analysis of the students' texts revealed that they followed diverse structural patterns that we classified as: listing and specifying; weighing advantages; and 
problem solving, which we illustrate below. The examples provided have not been modified and thus may show grammatical or lexical mistakes (see appendix for complete examples).

\subsection{Listing and specifying}

It refers to the description of a set of elements or events that are in some way associated either because they are linked chronologically or because there exists a logical connection between them. Hence, there is certain iconicity between text structure and the order of events, which can be reconciled with the SOURCE-PATHGOAL schema previously described.

These types of texts start with a paragraph that provides the reader with a general overview of the text content and outlines how information will be sequenced. As illustrated in the example below, this organizational format parallels the planning stage of a given trajectory -how to get there from here-:

\section{1) Planning stage:}

In this text we will explain one of the most important experiments of the XIX century. This experiment provided big information to Albert Einstein for developing his Relativity theory. You will see how some scientists explained the phenomenon before relativity appeared at the beginnings of the XX century (UBA0007-ENG-01).

Hence, the introduction sets out an "itinerary," i.e., an ordered set of historical events or states. This is coherent with the logic of the timeline of the path: movement along a path from one point to another implies the passing of time. This is also consistent with the continuity hypothesis, which asserts that readers expect the order in which events are reported in a text should match their chronological order in the world (Mandler 1986). Chronologically structured texts do just this: a text develops an idea, from the topic description (i.e., the source) to the conclusion (i.e., the destination), passing through various intermediate stages (i.e., the intermediate points along the path). Furthermore, if no obstacle blocks further progress, the reader will be successfully guided to the intended destination (usually the present state of affairs). Hence, progress in a chronologically ordered expository text corresponds very tightly with progress in space (i.e., the SOURCE-PATH-GOAL schema). 
Consider the rest of the text (which we have broken up into six blocks):

2) Setting up the situation:

The experiment was done with one partial mirror, two total mirrors and a very precise interferometer. [...] (UBA0007-ENG-01).

3) Treatment in the $19^{\text {th }}$ century:

We will see how scientist of the XIX century explained it. [...] (UBA0007-ENG-01).

4) Einstein's theory:

Until Albert Einstein published his relativity theory, this could not be explained (UBA0007ENG-01).

5) Acceptance of the theory today:

Today we know that length depends on the reference system and the relativity theory is accepted on the science community. [...] (UBA0007-ENG-01).

6) Conclusion or future avenues:

it's in our hands giving a good use to new knowledge. ¿When will science radically changes another time? I don't know, but we will wait for a long time (UBA0007-ENG-01).

In the text at hand, the subject matter deals with the origins of the theory of relativity by describing how this phenomenon was explained during the 19th century up until Albert Einstein formulated the theory of relativity. The text does not contain cohesive devices (e.g., discourse markers). However, given the fact that it is generally accepted that coherence does not lie in the text itself, but it is rather a characteristic of the cognitive representation that writers and readers construct on the basis of the text (Garnham and Oakhill 1996; Sanders, Spooren and Noordman 1993; Zwann and Radvansky 1998), the chronological ordering of the text, which rests on our world knowledge, and the use of time expressions such as Scientist of XIX century, until, nowadays or today, which mark the discourse progress towards the present state of affairs, aid coherence. Each point along the path, therefore, is identified by means of linguistic expressions expressing time. These intermediate locations are necessary to proceed; they link the source and the goal. In order to take a step forward, discourse must pass through each intermediate location until it arrives at its final destination: the present-day relevance of the theory of relativity. 


\subsection{Weighing-Advantages}

It describes and evaluates the topic of discourse in terms of its advantages and disadvantages. Texts of this type, which perform a double function - both informative and argumentative - are also an integral part of expository writing since their primary purpose is to deliver information about an issue, method or idea. Thus, the text provides readers with facts while also evaluating them to finally reach an informed conclusion. In this context, arguments act as forces that lead to a particular goal/conclusion. That is why it is argued that force dynamics partially structures discourse and argumentation (Talmy 2000).

Weighing-of-advantages is an example of how the interaction of the SOURCE-PATH-GOAL schema with force-dynamics plays a part in the way we conceptualize argumentation in the domain of discourse. In the next text analyzed herein, discourse takes as a starting point a review of the present state of affairs in wireless communication and one of its protocols, Bluetooth, whose properties and advantages are outlined (see example 1 below). Note that the pros are immediately blocked by the cons, which are introduced by the logic gater nevertheless. This effectively blocks the progress of the argument towards the intended destination (i.e., to highlight the role of Bluetooth as a valuable wireless protocol), as the set of sequentially ordered drawbacks lead one to conclude that the efficiency of Bluetooth is lower when compared with other protocols.

1) Pretext and opening argument:

In the last years, wireless communications have become something important in our daily life. We are able to talk on a mobile phone or connect to the Internet using an USB modem thanks to wireless communications. In these situations, wireless protocols play a key role because they are the basis of the whole process of communication. One of the most known and most used wireless protocols is Bluetooth (UBA0002-ENG-01).

2) Pros:

... Bluetooth has several advantages that have made it a widely used standard. [...] (UBA0002-ENG-01).

3) Cons:

Nevertheless, Bluetooth has some drawbacks that should be taken into account. (UBA0002-ENG-01). 
As a result, the argument stating the disadvantages of Bluetooth blocks the initial argument concerning its positive aspects and, hence, displaces it.
4) Conclusion:
In conclusion, Bluetooth has certain assets such us low power consumption, high level of integration and standardization that have made it suitable for lots of purposes. However, it has some lacks in security and scope that can limit the use in some areas. But the question is, how much time will need engineers to create a new standard of wireless communications with better characteristics that will replace Bluetooth? (UBA0002-ENG-01).

The endpoint of the path (the conclusion) is presented as a consequence of the facts previously exposed that invite to explore new avenues.

\subsection{Problem solving}

It spells out a problem and then describes or proposes a solution. In this case, a step by step description of the sequence of events involved in the solving of the problem can also be provided once the problem or question that needs to be solved is presented. Problem-solution is a common structural pattern. We believe that this might have to do with the fact that causal relations are among the most basic relations in constructing a coherent mental representation of narratives and expository texts (see Millis and Graesser 1994; Singer and Gagnon 1999). These studies show that readers expect to identify the causes and consequences of the events described in a text, just as they do when trying to understand and structure their environment (Trabasso, Secco and van den Broek 1984).

A possible explanation for the frequent use of the problem-solution organizational pattern is that, when reading, subjects bring with them certain structural expectations about texts, namely that a text tends to follow the sequence: introduction, body, and conclusion. Similarly, when a text introduces a problem, the reader's schematic knowledge of the problem-solutions structure is activated (Mulder 2008).

This might explain why writers in our corpus adopt this causal pattern when describing how certain technological systems have been developed to solve a problem.

Take, for instance, the following example, which approaches the problem of achieving a $3 \mathrm{D}$ effect with a $2 \mathrm{D}$ medium. 


\section{1) Problem:}

The depth effect or 3D effect is what makes the spectator believe that a meteorite will crush against him or a dinosaur will attack the whole audience. To achieve that in a 2D support as the cinema screen, we need to send a different image to each eye of the viewer, as it happens in real life (UBA0003-ENG-01).

Here, deficits in 3D technology are presented as problems to be solved; the strategies, methods or systems developed in response to these problems are depicted as possible solutions. In terms of metaphorical correspondences, problems are presented as the starting point (i.e., the source) and solutions as the path to a conclusion. Once the problem has been stated, different solutions may be provided and described in detail (along with the monetary difficulties they engender):

\footnotetext{
2) Solution:

To separate the right picture and the left picture there are several methods, but the most used in cinema are: anaglyphs, polarized glasses or shutter glasses... Both systems, polarized and shutter glasses, need a special projector, and it means an investment of money that not all theatres can afford. Anyway, with the appearance of the digital cinema, it is compulsory to change the projector, the screen and the whole room (UBA0003-ENG-01).
}

This sort of argumentation fits well with the SOURCE-PATH-GOAL schema. By going from an unsolved problem to a solved problem the writer can map the organization of the text onto that of a trajectory leading from one place to another place. Hence, because both writers and readers share this intuition, this type of text structure is "reader friendly".

\section{Discussion}

The previous analysis illustrates how various text structures (sequence, comparison-contrast and problem-solution) map onto the SOURCE-PATH-GOAL schema. There is an initial stage of "pretext and planning" of the journey to be undertaken from the source to the goal. We posit that this stage maps onto the introduction of a discursive text; we also posit that the source constituent of the schema maps onto the description of the topic of the text and the goal maps onto the text's conclusion. Between the source and the goal, there is a series of points that make up the path. These intermediate points map onto the various moves that 
writers make to attain their goal, in the case of the texts analyzed herein: listing and specifying, weighing advantages and problem solving.

This analysis leads us to think that the SOURCE-PATH-GOAL SCHEMA in combination with force-dynamics lends structure to the abstract domain of expository texts via the journey metaphor. Moreover, it shows that the SOURCEPATH-GOAL SCHEMA is flexible enough to accommodate content that is ordered chronologically and that, in conjunction with Talmy's theory of force dynamics, it can describe the structure of analytic-argumentative texts that ponder the pros and cons of a given argument. Finally, our analysis also suggests that the SOURCEPATH-GOAL SCHEMA is also coherent with the problem-solution text pattern where problems are presented as the starting point of the journey and solutions as the path to a conclusion (i.e., goal). Thus, the TEXT AS JOURNEY metaphor allows an inferential process that guides the different stages of writing:

1. Just as a journey requires a planning stage, so does expository writing.

2. Just as looping back on a whim to somewhere is inefficient and annoying for fellow travelers, digressions in writing have a similar effect on the reader. Thus, guiding the reader from the premises of an argument to a sound conclusion is best achieved by moving forward in a precise and calculated fashion.

3. All things being equal, the shortest distance between two points is a straight line; if writers follow this logic, then their texts should be much more linear and to the point

To be sure, we are not arguing that this construal of text organization exhausts all possible expository organizational patterns or that it is at odds with traditional descriptions of text structure. Rather, we believe it holds the possibility of complementing them. For example, whereas it is difficult to derive clear inferences from the notion of body (used when text structure is described as made of three parts: introduction, body and conclusion), a path can easily be broken up into intermediate points that must be touched upon in order to reach the desired goal. In other words, inferences from the logic of journeys can be easily mapped onto the logic of writing and be an effective tool to approach the analysis of text structure.

\section{Conclusion}

The analysis offered in this article, in combination with previous research on the metaphorical conceptualization of writing (Tobin 1989; Tomlinson 2005; 
Eubanks 2011), suggests that the WRITING IS JOURNEYING metaphor can be a useful tool for approaching text structure analysis and unifying multiple expository organizational patterns by mapping them onto the SOURCE-PATH-GOAL schema. In this sense, metaphor can be a particularly useful strategy to make explicit conventional ways of thinking about composition and text macrostructure and serve as a vehicle for communication about the organizational format of expository texts in the academic context.

This approach to discourse organization may have substantial advantages, in particular, for L2 learners with a lower linguistic proficiency, since planning (i.e., operations involving the retrieval and sequencing of information) seems to be influenced by the writer's degree of proficiency in the L2. As Schoonen et al. (2009) point out, less-proficient writers can become so absorbed in struggling with the language that writing processes such as planning or monitoring can be inhibited. This situation has consequences for the overall structure of the text, given the fact that the planning process is central in the organization of the text content (Flower and Hayes 1981). Bearing this in mind, if learners' awareness of their metaphorical knowledge of discourse structure is potentiated by explicit teaching, the process of planning could be less demanding and the quality of the ultimate written product, in particular its internal organization, could improve.

This approach to text structure could also help to improve reading skills. Research on reading comprehension has strongly emphasized the importance that recognizing text organization has for effective reading (Floris and Divina 2009; Meyer et al. 1989; Kintsch and Vipond 2014) and that text organization awareness is the most difficult reading skill for learners (Floris and Divina 2009). Hence, the use of the journeying metaphor, which makes available the possibility of applying our embodied experience, on which metaphors are based, to make inferences about text structure, could contribute to making more understandable the intangible notion of text structure by contrasting it with a more basic and structured reality.

Metaphorical construals have a significant impact on reasoning (Gentner and Gentner 1983; Thibodeau and Boroditsky 2011, 2013). Hence, we believe that the theoretical framework described here can be beneficial to text researchers, professors and students alike. It is our hope that future studies will also support the effectiveness of this proposal. In this sense, this article can be viewed as a first step towards that goal. 


\section{References}

ALLBRITTON, D. W. (1995). "When metaphors function as schemas: Some cognitive effects of conceptual metaphors". Metaphor and Symbolic Activity 10: 33-46.

ALLBRITTON, D. W., MCKOON, G. and GERRIG, R. J. (1995). "Metaphorbased schemas and text representations: Making connections through conceptual metaphors". Journal of Experimental Psychology: Learning, Memory, and Cognition 21 (3): 612-625.

CASTAÑO, E. (2012). The Embodied Basis of Discourse Coherence. (Unpublished doctoral dissertation). Universidad de Barcelona, Barcelona.

CASTAÑO, E., HILFERTY, J. and VERDAGUER, I. (2013). "The Metaphorical Basis of Discourse Structure" in Biomedical English: A Corpus-based Approach. (Eds. I. Verdaguer, N. Laso and D. Salazar). Amsterdam/New York: John Benjamins: 165-184.

DICKSON, S. V., SIMMONS, D. and KAMEENUI, E. J. (1995). "Instruction in expository text: A focus on compare/contrast structure". LD Forum 20: $8-15$.

ELBOW, P. (2006). "The music of form: rethinking organization in writing". College Composition and Communication 57 (4): 620-666.

EUBANKS, P. E. (2011). Metaphor and writing: figurative thought in the discourse of written communication. Cambridge: Cambridge University Press.

FLORIS, F. D. and DIVINA, M. (2009). "A study on the reading skills of EFL university students". TEFLIN Journal 20 (1): 37-46.

FLOWER, L. and HAYES, J. (1981). "A cognitive process theory of writing". College Composition and Communication 32: 365-87.

GARNHAM, A. and OAKHILL, J. V. (1996). "The mental models theory of language comprehension" in Models of Understanding Text. (Eds. B. K. Britton and A. C. Graesser). Hillsdale, New Jersey: Lawrence Erlbaum: 313-339.

GENTNER, D. and GENTNER, D. R. (1983). "Flowing waters and teeming crowds: mental models of electricity" in Mental Models. (Eds. D. Gentner and A. L. Stevens). Hillsdale, New Jersey: Lawrence Erlbaum: 99-129.

GHAITH, G. M. and HARKOUSS, S. (2003). "Role of Text Structure Awareness in the Recall of Expository Discourse". Foreign Language Annals 36 (1): 86-96.

GOATLY, A. (1997). The Language of Metaphors. London: Routledge. 
GOLDMAN, S. R. and RAKESTRAW, J. A. (2000). "Structural Aspects of Constructing Meaning from Text" in Handbook of Reading Research. (Eds. M. L. Kamil et al.). Mahwah, New Jersey: Erlbaum: 311-336.

HAMPE, B. (Ed.) (2017). Metaphor: Embodied Cognition and Discourse. Cambridge: Cambridge University Press.

HURTIENNE, J. and BLESSING, L. (2007). "Design for Intuitive Use - Testing image schema theory for user interface design". 16th International Conference on Engineering Design, Proceedings of the conference 386: 1-12.

HYLAND, K. (2007). "Genre pedagogy: language, literacy and L2 writing instruction". Journal of Second Language Writing 16 (3): 148-164.

JOHNSON, M. (1987). The Body in the Mind: The Bodily Basis of meaning, Imagination, and Reason. Chicago: University of Chicago Press.

KIBBLE, R. and POWER, R. (2004). "Optimizing Referential Coherence in Text Generation". Computational Linguistics 30 (4): 401-416.

KIMMEL, M. (2005). "From Metaphor to the 'Mental Sketchpad': Literary Macrostructure and Compound Image Schemas in Heart of Darkness". Metaphor and Symbol 20 (3): 199-238.

KIMMEL, M. (2008). "Image schemas in narrative macrostructure: combining cognitive linguistic with psycholinguistic approaches" in New Beginnings in Literary Studies. (Eds. W. Van Peer and J. Auracher). Newcastle: Cambridge Scholars: $158-184$.

KIMMEL, M. (2013). "The conceptual metaphors of narrative structure: Gestural evidence for spatialized form in storytelling". PJOS 5 (2): 75-123.

KINTSCH, W. and VIPOND, D. (2014). "Reading comprehension and readability in educational practice and psychological theory" in Perspectives on Learning and Memory (Ed. L. G. Nilsson). New York and London: Psychology Press: 329-365.

KUSIAK-PISOWACKA, M. (2016). "Mental Model Theories in reading research and Instruction" in Working in Text and Around Text in Foreign Language Environments. (Eds. H. Chodkiewicz et al.). Switzerland: Springer: 25-37.

LAKOFF, G. and JOHNSON, M. (1980). Metaphors We Live By. Chicago: The University of Chicago Press.

LAKOFF, G. (1987). Women, Fire, and Dangerous Things: What Categories Reveal about the Mind. Chicago: The University of Chicago Press.

LAKOFF, G. (1993). "The contemporary theory of metaphor" in Metaphor and Thought. (Ed. A. Ortony). Cambridge: Cambridge University Press: 202251. 
LAKOFF, G. (2014). "Mapping the brain's metaphor circuitry: metaphorical thought in everyday reason". Frontiers in Human Neuroscience 8. https:// doi.org/10.3389/fnhum.2014.00958.

LAU, R. R. and SCHLESINGER, M. (2005). "Policy frames, metaphorical reasoning, and support for public policies". Political Psychology 26: 77-114.

MANDLER, M. J. (1986). "On the comprehension of temporal order". Language and Cognitive Processes 1: 309-320.

MATSUDA, P. K., CANAGARAJAH, A. S., HARKLAU, L., HYLAND, K. and WARSCHAUER, M. (2003). "Changing currents in second language writing research: A colloquium". Journal of Second Language Writing 12 (2): 151-179.

MEYER, B. J. F. (1999). "The importance of text structure in everyday reading" in Understanding language understanding: Computational models of reading and understanding. (Eds. A. Ram and K. Moorman). Cambridge, MA: MIT Press: 227-252.

MEYER, B. J. F., TALBOT, A. P., POON, L. W. and JOHNSON, M. M. (2001). "Effects of structure strategy instruction on text recall of older African American Adults" in Literacy in African Americans communities. (Eds. J. L. Harris et al.). Mahwah, New Jersey: Erlbaum: 233-263.

MEYER, B. J. F., YOUNG, C. J. and BARTLETT, B. J. (1989). Memory improved: Reading and memory enhancement across the life span through strategic text structures. New York and London: Psychology Press.

MEYER, B. J. F. and POON, L.W. (2004). "Effects of structure strategy training and signaling on recall of text" in Theoretical models and processes of reading. (Eds. R. B. Ruddell and N. J. Unrau). Newark, Delaware: International Reading Association: 810-851.

MILLIS, K. and GRAESSER, A. C. (1994). "The time-course of constructing knowledge-based inferences for scientific texts". Journal of Memory and Language 33: 583-599.

MULDER, G. (2008). Understanding causal coherence relations. (Unpublished doctoral dissertation). Utrecht: Landelijke Onderzoekschool Taalwetenschap.

MURRAY, J. D. (1997). "Connectives and narrative text: The role of continuity". Memory and Cognition 25: 227-236.

PEARSON, P. and RAPHAEL, T. (1990). "Reading comprehension as a dimension of thinking" in Dimensions of thinking and cognitive instruction: Implications for reform. (Eds. B. F. Jones and L. I. Idol). Hillsdale New Jersey: Lawrence: 209-240. 
PEÑA CERVEL, M. S. (2011). "Macbeth Revisited: A cognitive analysis". Metaphor and Symbol 26: 1-22.

PONTEROTTO, D. (2003). "The cohesive role of cognitive metaphor in discourse and conversation" in Metaphor and Metonymy at the Crossroads. A Cognitive Perspective. (Ed. A. Barcelona). Berlin: Mouton de Gruyter: 283-298.

PONTEROTTO, D. (2007). "Conceptual Metaphor and Text Development: a Narratological Perspective". Cultural Studies Journal of Universitat Jaume I 5: 59-73.

RAPHAEL, T. E. and ENGLERT, C. S. (1990). "Writing and reading: Partners in constructing meaning". The Reading Teacher 43: 388-400.

RICHARDSON, J. and MORGAN, R. (2003). Reading to Learn in the Content Areas. Belmont, CA: Thomson-Wadsworth.

ROBINS, S. and MAYER, R. E. (2000). "The metaphor framing effect: Metaphorical reasoning about text-based dilemmas". Discourse Processes 30: 57-86.

SALMANI-NODOUSHAN, M. A. (2010). "The impact of formal schemata on L3 reading recall". International Journal of Language Studies (IJLS) 4 (4): 357-372.

SANDERS, T. J. M. and SCHILPEROORD, J. (2006). "Text structure as a window on the cognition of writing; How text analysis provides insights in writing products and writing processes" in Handbook of Writing Research. (Eds. C. MacArthur; S. Graham and J. Fitzgerald). New York: Guilford Press: 386-402.

SANDERS, T., SPOOREN, W. and NOORDMAN, L. (1993). "Coherence Relations in a Cognitive Theory of Discourse Representation". Cognitive Linguistics 4 (2): 93-133.

SANDERS, T. and NOORDMAN, L. G. M. (2000). "The role of coherence relations and their linguistic markers in text processing". Discourse Processes 29: 37-60.

SCHOONEN, R., SNELLINGS, P., STEVENSON, M. and VAN GELDEREN, A. (2009). "Towards a blueprint of the foreign language writer: The linguistic and cognitive demands of foreign language writing" in Writing in foreign language contexts: Learning, teaching and research. (Ed. R. M. Manchón). Bristol/Buffalo/Toronto: Multilingual Matters: 77-101.

SEMINO, E. (2008). Metaphor in Discourse. Cambridge: Cambridge University Press.

SERIG, D. (2008). "Understanding the conceptual landscape of visual metaphor". Teaching Artist Journal 6 (1): 41-50. 
SINGER, M. and GAGNON, N. (1999). "Detecting causal inconsistencies in scientific text" in Narrative comprehension, causality, and coherence: Essays in honor of Tom Trabasso. (Eds. S. R. Goldman, A. Graesser and P. van den Broek). Mahwah, New Jersey: Lawrence Erlbaum: 179-194.

TALMY, L. (2000). Toward a Cognitive Semantics, vol. I. Cambridge: The Mitt Press.

THIBODEAU, P. H. and BORODITSKY, L. (2011). "Metaphors we think with: the role of metaphor in reasoning". PLOS ONE 6 (2): e16782.

THIBODEAU, P. H. and BORODITSKY, L. (2013). "Natural language metaphors covertly influence reasoning". PLoS ONE 8 (1): e52961.

TOBIN, L. (1989). "Bridging Gaps: Analyzing Our Students' Metaphors for Composing". College Composition and Communication 40 (4): 444-458.

TOMLINSON, B. (2005). Authors on writing: Metaphors and intellectual labor. Houndmills, Basingstoke, Hampshire; New York: Palgrave Macmillan.

TRABASSO, T., SECCO, T. and VAN DEN BROEK, P. W. (1984). "Causal cohesion and story coherence" in Learning and comprehension of text. (Eds. H. Mandler, N. L. Stein and T. Trabasso). Hillsdale, NJ: Erlbaum: 83-111.

VAHIDI, S. (2008). "The impact of EFL learners' rhetorical organization awareness on English academic/expository text comprehension". Pazhuheshe Zabanha-ye Khareji 41: 145-158.

VIRTUE, S., VAN DEN BROEK, P. and LINDERHOLM, T. (2006). "Hemispheric processing of inferences: The effects of textual constraint and workingmemory capacity". Memory and Cognition 34 (6): 1341-1354.

WONG, B.Y.L. (2000). "Writing strategies instruction for expository essays for adolescents with and without disabilities". Topics in Language Disorders 20: 29-44.

YOUNG, T. A. and HADAWAY, N. L. (Eds.) (2006). Supporting the literacy development of English learners: Increasing success in all classrooms. Newark, DE: International Reading Association.

ZWAAN, R. and RADVANSKY, G. (1998). "Situation models in language comprehension and memory". Psychological Bulletin 123 (2): 162-185.

ZWAAN, R. A. and SINGER, M. (2003). "Text comprehension" in Handbook of discourse processes. (Eds. A.C. Graesser, M. A. Gernsbacher and S. R. Goldman). Mahwah, New Jersey: Erlbaum: 83-121. 


\section{APPENDIX}

\section{Listing and specifying}

1. Planning stage:

In this text we will explain one of the most important experiments of the XIX century. This experiment provided big information to Albert Einstein for developing his Relativity theory. You will see how some scientists explained the phenomenon before relativity appeared at the beginnings of the XX century (UBA0007-ENG-01).

2. Set up the situation:

The experiment was done with one partial mirror, two total mirrors and a very precise interferometer. The light focus is the sun. Earth is moving around the sun and gets in the same point in a year. This relative speed is near $10 \mathrm{Km} / \mathrm{s}$, so it seems the light should arrive at different time depending on the way. However, the results of the experiment were not the expected ones. The light needed the same time on the both ways! (UBA0007-ENG-01).

3. Treatment in the $19^{\text {th }}$ century:

We will see how scientist of the XIX century explained it. Lorentz was a very important physic. He studied the electromagnetic fields. He was the first who gave a solution to that new problem. This solution was near the true but not at all. He considered that one of the light ways of the experiment was getting shorter. He called this phenomenon: the length contraction (UBA0007ENG-01).

\section{Einstein's theory:}

Until Albert Einstein published his relativity theory, this could not be explained (UBA0007-ENG-01). 


\section{Acceptance of the theory today:}

Today we know that length depends on the reference system and the relativity theory is accepted on the science community. The Most famous application is the nuclear energy, also GPS uses aspects of the theory and a lot of medical machines are using it as well (UBA0007-ENG-01).

\section{Conclusion or future avenues:}

it's in our hands giving a good use to new knowledge. ¿When will science radically changes another time? I don't know, but we will wait for a long time (UBA0007-ENG-01).

\section{Weighing-Advantages}

\section{Pretext and opening argument:}

In the last years, wireless communications have become something important in our daily life. We are able to talk on a mobile phone or connect to the Internet using an USB modem thanks to wireless communications. In these situations wireless protocols play a key role because they are the basis of the whole process of communication. One of the most known and most used wireless protocols is Bluetooth (UBA0002-ENG-01).

\section{Pros:}

Bluetooth has several advantages that have made it a widely used standard. It has a lot of applications in very different areas such as mobile file transmission, baby monitors, headphones or garage-door openers. Another advantageous thing is that, as a standard, it does not have any incompatibility problems with devices bought in different regions. And the last benefit, but no less important, is its level of integration: Bluetooth devices can be placed in small areas due to their reduced dimensions (UBA0002-ENG-01).

\section{Cons:}

Nevertheless, Bluetooth has some drawbacks that should be taken into account. First, it does not implement a security protocol, so an unwanted person 
could intercept the data that are been transmitted (which is known as bluejacking). Second, its limited scope is also a big problem: both terminals have to be near each other in order to establish a communication between them as a consequence of the low power transmitted. And finally, the bandwidth used by Bluetooth is very wide for its bit rate. Hence, the efficiency is much lower compared with other wireless protocols (UBA0002-ENG-01).

\section{Conclusion}

In conclusion, Bluetooth has certain assets such us low power consumption, high level of integration and standardization that have made it suitable for lots of purposes. However, it has some lacks in security and scope that can limit the use in some areas. But the question is, how much time will need engineers to create a new standard of wireless communications with better characteristics that will replace Bluetooth? (UBA0002-ENG-01).

\section{Problem solving}

\section{Problem:}

The depth effect or 3D effect is what makes the spectator believe that a meteorite will crush against him or a dinosaur will attack the whole audience. To achieve that in a 2D support as the cinema screen, we need to send a different image to each eye of the viewer, as it happens in real life (UBA0003-ENG-01).

\section{Solution:}

To separate the right picture and the left picture there are several methods, but the most used in cinema are: anaglyphs, polarized glasses or shutter glasses... Both systems, polarized and shutter glasses, need a special projector, and it means an investment of money that not all theatres can afford. Anyway, with the appearance of the digital cinema, it is compulsory to change the projector, the screen and the whole room (UBA0003-ENG-01). 